Top up degree now available for dental technicians

The People's College Nottingham has been validated by De Montfort University to offer a BSc (Hons) degree in Dental Technology linked to the new General Dental Council (GDC) registration. The degree will allow individuals who are registered dental technicians, or who have a current registrable qualification in dental technology, to study for a BSc (Hons) degree. The course will also be open to those who have accredited prior learning in dental technology, such as a City and Guilds, plus vocational competence.

The College will be offering the degree by a part time study route based at its central Nottingham Dental Care Professional School. The final degree qualification will be awarded by De Montfort University, which has also supported the development of the programme alongside the GDC, the Dental Laboratories Association and the Dental Technicians Association.

College Principal David Gibson CBE said:

"This Dental Technology BSc (Hons) degree will give the dental technician profession a direct route to recognition of its high level of technology, which it justly deserves. The inclusion in this degree of Clinical Integration, along with making vocational experience count, shows a real link to the development of modern health care teams in support of patient care."

Prospective students can obtain an information pack by contacting Simon Torres, Dental Technicians Admissions Tutor, at simon_torres@peoples.ac.uk.

\section{Bright Bites initiative launched}

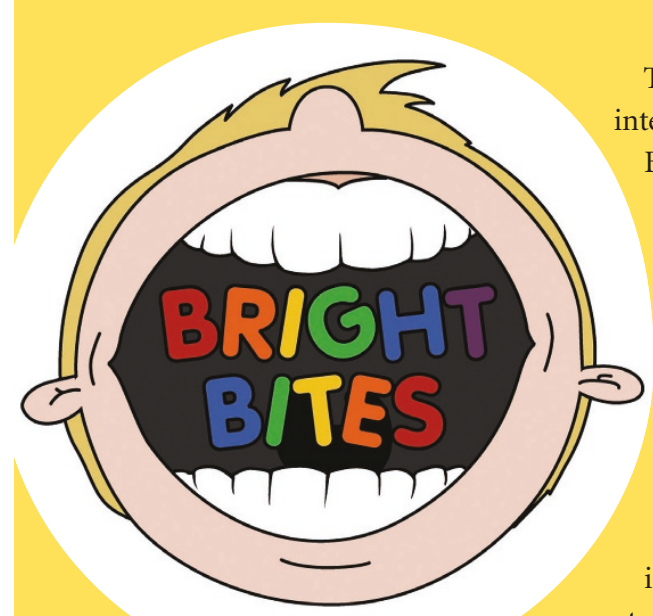

The oral health charity Dentaid has launched a major new education initiative. Developed with funding from the Department of Health and official sponsors Aquafresh and Denplan, Bright Bites is a comprehensive learning tool designed for dental professionals and schools to teach UK children the importance of good oral hygiene and a balanced diet.
The programme is based around an interactive CD-Rom featuring 'Charlie', the Bright Bites hero. Children explore his house visiting different rooms, each teaching them about a different aspect of oral health and diet using games about their own teeth, children can find out about the teeth and diet of different animals, and the role of the tongue and saliva.

The CD-Rom forms part of a teaching pack that has been distributed to all state primary schools in England to help meet the objectives of the Key Stage 2 curriculum. The pack has also been designed with dental professionals in mind, with a CD-only version available to run in the waiting room and retail packs that can be sold by practices either on a profit making basis, or as a not-for-profit option to support Dentaid's charity work around the world. Further information on the project can be found at www.brightbites.org. and video clips. As well as learning

\section{Continuing support for DCPs}

Dental Protection Ltd has once again teamed up with Schülke \& Mayr to announce the Premier Award 2006, the prestigious award that supports DCPs' vital role within the dental team.

The award recognises initiatives to increase the awareness and management of risks in clinical dentistry. Kevin Lewis, Director of Dental Protection, said: "The annual collaboration between Schülke and Mayr and Dental Protection is an ideal forum to learn about risk management. It is very much a team exercise and I was delighted last year to see the involvement of so many DCPs. They are essential members of every dental team and the Premier Award is a great way to recognise their contribution."

With GDC registration imminent and an expanding role within the dental team, a $\mathfrak{E} 1,000$ prize fund is being offered for DCPs this year. The award will be presented during the Premier Symposium in early December.

\section{New courses from Eastman CPD}

Eastman CPD has announced new courses for dental nurses and dental technicians. Designed to improve skills and understanding, the courses cover a variety of topics.

Dental nurses have the option of three one-day courses entitled Cross Infection Control, Health and Safety, and Implants - the Nurse's Role. The courses for dental technicians take place over two days and have the titles Ceramics for Implants, Integrating Implants into the Laboratory, and How to Develop the Clinician/Technician Dialogue - a course that Eastman hopes dentists and technicians will attend as a team.

The launch of the new courses is very timely given the introduction of compulsory CPD for all dental team members from 2008. More details are available from Karen Rhatigan on 02079051244 or by email at k.rhatigan@eastman.ucl.ac.uk. The dates of the courses can also be found in our Classified section ( $p$ 49) under Education and Training.

eastman $=$ 